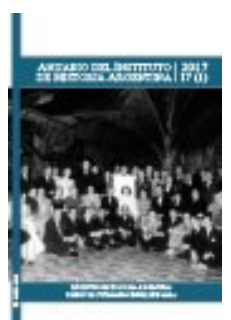

Anuario del Instituto de Historia Argentina, vol. 17, nº 1, e035, junio 2017.

ISSN 2314-257X

Universidad Nacional de La Plata.

Facultad de Humanidades y Ciencias de la Educación.

Centro de Historia Argentina y Americana

\title{
Pelos pequenos trabalhadores do Novo Mundo: OIT e trabalho infantojuvenil nas Américas (1936-1939)
}

\author{
For the little workers of the New World: ILO and child labor in the \\ Americas (1936-1939)
}

\section{José Pacheco dos Santos Júnior *}

* Universidade de São Paulo. Doutorando em História Econômica, Brasil | josepsjunior@usp.br

\section{PALAVRAS-CHAVE}

Organização Internacional do Trabalho

Trabalho infantojuvenil

Conferências Americanas do

Trabalho (1936-1939)

KEYWORDS

International Labour

Organization

Child labor

American Labour

Conferences (1936-1939)

\section{RESUMO}

Criada em 1919, a Organiza ção Internacional do Trabalho assumiu ousada tarefa: normatizar o mundo do trabalho e consolidar o ideal de justiça social como forma de enraizar a paz mundial. Elegendo essa agência como objeto de estudo, o artigo objetiva analisar a formulação e os propósitos que definiram as resoluções sobre o trabalho de crianças e jovens discutidas e aprovadas nas duas primeiras Conferências Americanas do Trabalho, realizadas no Chile (1936) e em Cuba (1939). Sob o amparo da análise comparativa, a reflexão conclui que as resoluções advindas de tais fóruns não serviram apenas para regular, mas também conformar modelos ideais de infância e juventude. 
Em 1936, Jorge Amado publicava o seu romance Mar morto. Narrando as aventuras e desventuras dos homens que viviam e labutavam no cais de Salvador, Amado acentuou um traço da infância de Guma: o personagem herói do mar da Bahia que, aos onze anos de idade, "conduzia um saveiro e levantava um saco de farinha” (Amado, 2008 [1936], p.37).

Nesse mesmo ano, reuniram-se na capital do Chile, Santiago, pela primeira vez, os países americanos membros da Organização Internacional do Trabalho (OIT) dispostos a debater e apresentar resoluções acerca das necessidades específicas dos trabalhadores do "Novo Mundo". Com relevo, a questão do trabalho de crianças e jovens, em conjunto com o trabalho das mulheres, se impôs desde a convocatória expedida pelo diretor-geral da Organização, Harold Butler. Assim, através de análise comparativa, este artigo apresenta os resultados da pesquisa que visou compreender o quadro da normatização internacional do trabalho infantojuvenil, e o debate acerca do mesmo, efetivado pelos países americanos membros da OIT. A problemática específica norteou-se pela seguinte questão: como as Conferências Americanas do Trabalho no delicado período econômico do entreguerras reagiram e juridicizaram o labor de crianças e jovens? Para isso, o artigo elegeu a documentação resultante da Conferência de Santiago e de Havana buscando a lógica que moveu a formulação das resoluções que visaram tratar do trabalho precoce.

Primeiramente, pensar a infância e a juventude como categorias de análise não é tarefa simples. Permeada por uma infinidade de concepções que a sustentam em suas bases culturais, uma certeza se sobressai: a condição plural dessas categorias a ressoar e permitir as mais diversas ações e políticas destinadas aos sujeitos que contemplam. Em paralelo, encontra-se a questão do trabalho infantojuvenil. Apesar de algumas medidas tímidas encetadas nos Oitocentos, como nos Estados Unidos, por exemplo, em que vários estados da região nordeste, como cita Colin Heywood (2004), “também começaram a regulamentar o trabalho infantil na década de 1840, notadamente Massachusetts, Connecticut e Pensilvânia. Mais uma vez, porém, com pouca ou nenhuma aplicação” (p. 182); foi sobretudo ao final do século XIX que um debate mais denso sobre a regulação desse tipo de mão de obra passou a ser esboçado no plano internacional, o que de certo modo, influenciou o posicionamento de diversos ordenamentos jurídicos, como também reivindicações por sua implementação mundo afora.

Sobre esse contexto, Viviana Zelizer se afirmou dentro da Sociologia Econômica com a sua premiada obra publicada em 1985, Pricing the Priceless Child. Nesse livro, que se tornou clássico na historiografia mundial sobre o trabalho infantil, Zelizer conjuga fatores simbólicos e econômicos associados à infância nos Estados Unidos da transição do século XIX para o XX. Para ela, há, nesse período, "uma profunda transformação nos valores sentimentais e econômicos em relação às crianças, entre 1870 e 1930” (Zelizer, 1985, p. 3, tradução livre), havendo o "surgimento de uma criança economicamente 'sem valor', mas emocionalmente 'inestimável’” (Zelizer, 1985, p. 3, tradução livre). Sentimento este que provavelmente moveu o fotógrafo estadunidense Lewis Hine que em julho de 1915 flagrou Henry, um pequeno trabalhador numa fazenda de beterrabas dos Estados Unidos, que aos seis anos de idade declara: “eu nunca tenho descanso" (figura 1): 
Figura 1: "Eu nunca tenho descanso", disse Henry, pequeno trabalhador com seis anos de idade, fotografado em julho de 1915 pelo fotógrafo Lewis Hine. Wisconsin (EUA).

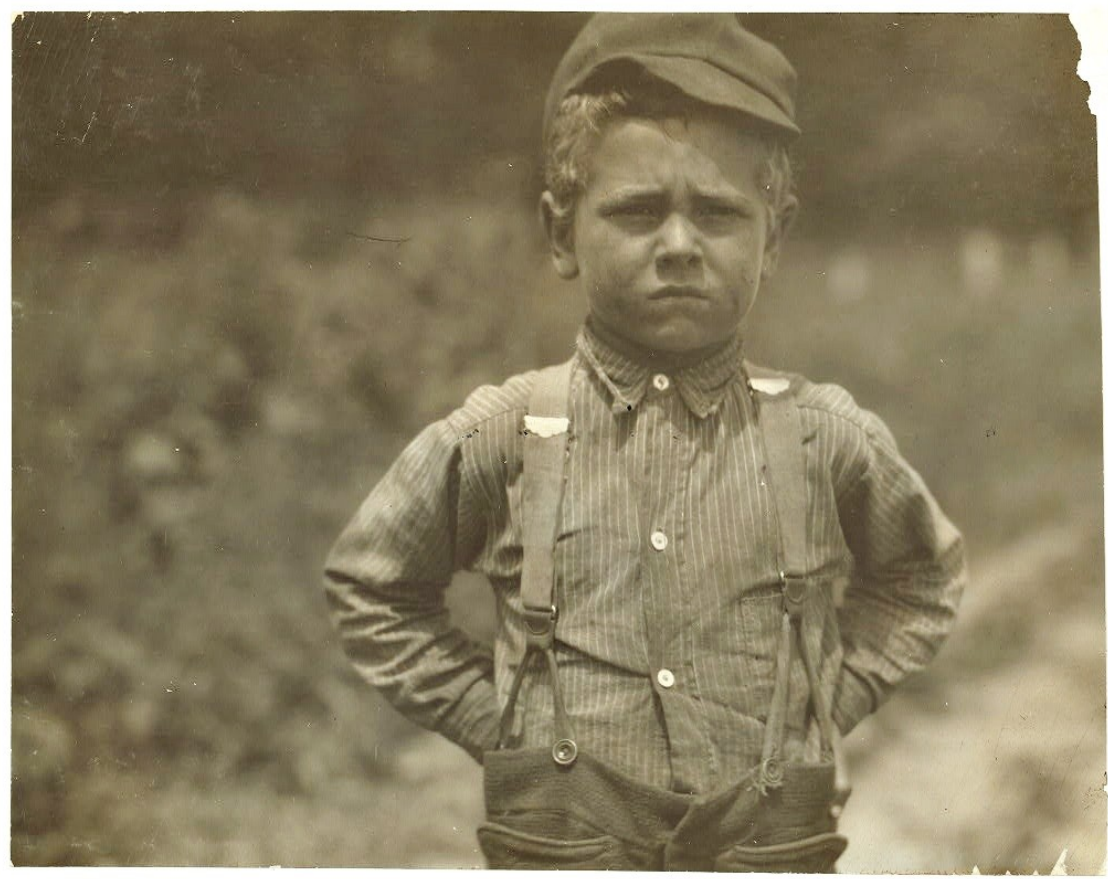

Fotografia: Lewis W. Hine (Wisconsin, Estados Unidos, julho de 1915). Fonte: Library of Congress, Prints and Photographs Division, National Child Labor Committee Collection, LC-DIG-nclc-00269

Num plano mais amplo, encontra-se a terceira Conferência de Berna, convocada pelo governo suíço e realizada em 1913, que teve por meta a fixação de duas novas convenções, como menciona Süssekind (1987): “a) a proibição do trabalho dos menores na indústria; b) a fixação da jornada máxima de dez horas para o trabalho das mulheres e dos menores” (p. 94). Apesar de aprovadas, essas normas esbarraram com o início da Primeira Guerra Mundial, motivo que impediu a execução da Conferência diplomática, agendada para setembro de 1914, que estabeleceria o corpo dos tratados multilaterais previstos para essa matéria.

Além disso, "três meses depois do armistício e logo após a instalação da Conferência da Paz, realizou-se a Conferência Sindical Internacional (Berna, fevereiro de 1919), com delegados dos países aliados e de outros Estados, sendo aprovada a 'Carta do Trabalho', na qual foram inseridos alguns princípios destinados ao futuro Tratado de Paz” (Süssekind, 1987, p. 96). Dentre eles, a proibição do trabalho noturno das mulheres e menores.

\section{A OIT e a questão do trabalho infantojuvenil}

Em 1919, logo ao t érmino da Primeira Guerra Mundial e como parte do intitulado Tratado de Versalhes surgiu a OIT com o ousado propósito de "melhorar as condições de trabalho para assegurar a paz mundial" (OIT, 1938, p. 8). Em particular, a proteção às crianças, adolescentes e mulheres já estava contida no preâmbulo de sua primeira Constituição e no teor de sua primeira produção normativa. Os debates nacionais e internacionais suscitados no limiar do século XX estimularam a inclusão do trabalho precoce como item da primeira Conferência Internacional do Trabalho da OIT, realizada em 1919. Nessa conferência, a OIT adotou seis convenções. A primeira, a limitação da jornada de trabalho a 8 diárias e 48 semanais, sintetizava uma das principais reivindicações do movimento sindical e operário do final do século XIX e começo do século XX. As demais convenções adotadas nessa ocasião referem-se à proteção à maternidade, à luta contra o desemprego, à definição da idade mínima de 14 anos para o trabalho na indústria e à proibição do trabalho noturno de mulheres e menores de 18 anos (OIT, s.f.). 
Como apontado, a atividade normativa da Organização desde a sua gênese se concentra em dois instrumentos jurídicos: as convenções, que são tratados multilaterais abertos à ratificação dos Estados-membros que, uma vez ratificados, passam a integrar a respectiva legislação nacional; e as recomendações, que são normas de caráter não obrigatório que podem servir de modelo para a elaboração de legislação interna. Conforme Gerry Rodgers et al (2009), “as convenções sobre a idade mínima adotadas entre 1919 e 1921 foram os primeiros instrumentos internacionais no âmbito dos direitos da criança, e se encontram também entre os primeiros em relação aos direitos humanos em geral” (p. 74, tradução livre).

O jurista Arnaldo Süssekind (1987) comenta que as normas da OIT devem ser submetidas à autoridade nacional competente para aprovar a ratificação da convenção ou para adotar as normas constantes das recomendações. A estrutura básica da Organização é constituída por três órgãos: 1) Conferência Internacional do Trabalho: assembleia geral de todos os Estados-membros da OIT, sendo seu órgão supremo e responsável pela execução da atividade normativa e deliberativa; 2) Conselho de Administração: órgão responsável pela função diretiva, como a definição de datas e locais das reuniões da Conferência Internacional do Trabalho, observação do processo de ratificação das convenções pelos Estados, além de organizar orçamentos e fiscalizar os gastos da OIT (Cf. Nascimento, 2010); 3) Repartição Internacional do Trabalho: como explica Süssekind (1987), a Repartição constitui o secretariado técnico-administrativo da Organização, exerce a função de centralizar e distribuir todas as informações acerca da regulamentação internacional das condições de vida e trabalho dos trabalhadores e, em particular, o estudo das questões a serem submetidas à discussão na Conferência, além de fomentar publicações atinentes à legislação comparada, oferecimento de assessoria aos países, quando solicitada, e promoção de programas de atividades práticas e de cooperação técnica. Além disso, a OIT é composta por uma estrutura tripartite, constituída por representantes de governos, patrões e trabalhadores.

Com a digitalização dos documentos oficiais da Organização, assim como através do desenvolvimento do ILO Century Project -projeto da OIT destinado a fortalecer a pesquisa histórica mundial acerca da história do trabalho e da própria Organização que fará 100 anos em 2019- e com a possibilidade de consulta presencial das diversas fontes da OIT em seu arquivo histórico e biblioteca em Genebra (Suíça), como também em seus vários escritórios regionais espalhados pelo mundo, as últimas décadas foram frutíferas em estudos acerca da história da OIT e da relação existente entre esta agência da ONU e seus países-membros.

Focado em examinar a campanha internacional fomentada pela OIT contra a exploração do trabalho infantil desde 1919, encontra-se David M. Smolin (2000, 1999) em seus artigos Strategic Choices in the International Campaign Against Child Labor e Conflict and Ideology in the International Campaign Against Child Labour, publicados respectivamente nas revistas Human Rights Quarterly e Hofstra Labor and Employment Law Journal. Contribuições fulcrais, os textos de Smolin apresentam uma periodização sobre a campanha da OIT relativa ao trabalho precoce composta por quatro fases: $1^{\text {a }}$-1919-1932-, o período das primeiras convenções, marcado pela aprovação de normas dedicadas à definição de idades mínimas para a admissão ao emprego em áreas econômicas específicas; 2a -1936-1965 -, período de revisão de algumas convenções e elevação das idades mínimas; $3^{\mathrm{a}}$-1973-, ano da aprovação da Convenção nº 138, considerada uma das convenções mais importantes da OIT, consagrada à elevação gradual da idade mínima para a admissão ao emprego; $4^{\text {a }}$-da década de 1990 aos dias atuais-, caracterizada entre outros fatores pelo desenvolvimento do Programa Internacional para a Eliminação do Trabalho Infantil (IPEC) e pelas normas de combate às piores formas de trabalho infantil.

Marianne Dahlén (2007), por sua vez, em sua tese The Negotiable Child. The ILO Child Labour Campaign 1919-1973, ao analisar o contexto da produção normativa e as motivações que definiram as idades mínimas para a admissão ao emprego aprovadas nas convenções e recomendações da OIT, entre 1919 e 1973, compreende que a infância é uma construção histórica e que a matéria legal é parte dessa construção. Para 
ela,

A campanha da idade m ínima foi modelada sobre a norma da infância na indústria ocidental. As normas e realidades da infância em outras partes do mundo foram negligenciadas, consideradas como fases provisórias e inferiores em relação à "norma” ocidental. Desta forma, houve duas infâncias separadas na campanha da idade mínima: a infância "normal” concebida para as condições ocidentais e "a outra" infância concebida para as condições "imperfeitas" das crianças pobres nos países colonizados e em desenvolvimento (Dahlén, 2007, p. 4, tradução livre).

Em concordância com esse ponto de vista, a articulação e circulação das normas internacionais sobre o trabalho infantojuvenil serviram para delimitar padrões e perfis de trabalhadores, como também normas condizentes às condições ideais reivindicadas pelos diversos segmentos que compunham as organizações internacionais, e a OIT, em específico. Se as convenções aprovadas em Washington -palco da Primeira Conferência Internacional do Trabalho- e em Genebra possuem as marcas das vozes de agentes dos quatro cantos do mundo, quais foram, afinal, as conviç̧ões particulares das Américas ao tratar dos pequenos trabalhadores?

\section{A Conferência de Santiago (Chile, 1936)}

Idealizada pelo governo chileno através de seu primeiro delegado, García Oldini, a ideia de uma conferência sediada no continente americano surgiu na Conferência Internacional do Trabalho de 1935, em Genebra. Na convocação expedida por Harold Butler aos países americanos membros da Organização em doze de julho de 1935, como destacou-se na introdução deste artigo, Butler comunica que a ordem do dia da Conferência seria composta por dois pontos: 1) exame, desde o ponto de vista de sua ratificação e aplicação, da situação das convenções internacionais do trabalho existentes, e em particular das convenções e recomendações relativas aos "seguros sociais" e das convenções e recomendações relativas às condições de trabalho das mulheres e das crianças; 2) exame das questões que ulteriormente puderam ser objeto de discussão na Conferência Internacional do Trabalho ${ }^{1}$.

O segundo ponto seria composto como enunciado por temas sugeridos pelos países participantes. Assim, em convocação enviada de Genebra, datada de onze de novembro de 1935, o Conselho de Administração anuncia que a Repartição Internacional do Trabalho "havia recebido certo número de sugestões acerca do segundo ponto da ordem do dia da Conferência, formulada por vários dos governos que participarão da mesma”ㄹ. Entre as sugestões recebidas, uma proposta enviada pelos Estados Unidos merece atenção: a elevação da idade mínima para a admissão ao trabalho, prevista pelas diferentes convenções da OIT sobre o trabalho de crianças, para dezesseis anos. Proposta esta extremamente ousada para o per íodo, já que em alguns países americanos a idade mínima para admissão ao emprego poderia chegar ao piso de doze anos de idade, como no México e na Nicarágua, ou a dez anos de idade para a legislação da Bolívia Convenção ${ }^{\circ}$ $138^{3}$.

As demais pautas indicadas incluíam a racionalização e redução das horas de trabalho na indústria têxtil proposta dos Estados Unidos-, questões atinentes a alimentação popular, níveis de salário-mínimo e condições de vida e trabalho dos empregados na agricultura -algumas das propostas do Chile ${ }^{4}-$.

Com a participação de dezenove países das Américas, a Conferência Americana de 1936 realizou-se em treze dias sob a presidência de Alejandro Serani Burgos, o Ministro do Trabalho chileno ${ }^{5}$. Mantendo a estrutura tripartite de representação que a Conferência Internacional do Trabalho também adota, as diversas delegações foram compostas por dois delegados governamentais, um delegado patronal e um delegado 
operário acompanhados por conselheiros técnicos. No entanto, apenas os delegados tiveram direito a voto. Além disso, o custeio de viagem e estadia dos participantes estariam sob a responsabilidade de seus governos.

O discurso do Ministro das Relações Exteriores do país anfitrião, Cruchaga Tocornal, na abertura da Conferência evidenciou a importância da OIT diante do mundo no pós-guerra:

Após a horrorosa tragédia que durante quatro anos assolou a humanidade, houve o esforço para encontrar as bases de um novo mundo e assegurar a paz entre as nações, surgiu espontaneamente a ideia primária da nova organização internacional: o homem como sujeito de direito internacional, com direitos e deveres que devem ser reconhecidos por todas as soberanias e a harmonia social como elemento necessário e fundamental. $\underline{6}$

As palavras de Tocornal não apenas permitem perceber a sua intenção de manifestar boas vindas aos diversos sujeitos que ali se encontravam, originados dos inúmeros rincões das Américas, mas, sobretudo, afirmar a centralidade do direito internacional no cenário jurídico coevo, como também o lugar, cada vez mais acentuado, da intervenção estatal na regulação econômica. Já Walter Riddell, presidente do Conselho de Administração, salienta o interesse que os países americanos demonstraram naqueles anos em relação à legislação trabalhista, “circunstância propícia para que a primeira Conferência desta natureza se realize com êxito no novo mundo" ${ }^{\text {? }}$. Como destaca o próprio Riddel, "este interesse foi atestado pelo fato de que das 109 ratificações de convenções do trabalho registradas nos últimos dois anos em Genebra, 73, ou seja, quase 70\% provêm dos países americanos ${ }^{8}$.

A flutuante representação operária dos países sul-americanos nas Conferências Internacionais do Trabalho ganharam ênfase na voz de Arthur Hayday, representante operário do Conselho de Administração. Hayday destaca que de "18 países, oito nunca enviaram um delegado representante dos operários a nenhuma das Conferências Internacionais: três países tenham feito apenas uma vez, e isso foi no ano de 1919”ํㅗ. Sobre as consequências da crise de 1929, Harold Butler registra que "me aventuro a crer que esta reunião dos países da América para examinar todas estas questões é singularmente oportuna. Um dos aspectos mais significativos da depressão tenha sido o de estimular a legislação social tanto na América do Norte como na América do Sul”10.

Em 13 de janeiro de 1936, iniciava-se a discussão acerca do Informe sobre o trabalho das mulheres e crianças. Sob a presidência de Frieda Miller, delegada governamental dos Estados Unidos, e por Allanita Diniz-Gonzalves (sic), conselheira técnica governamental do Brasil e escolhida para ser a relatora, a Comissão do Trabalho das Mulheres, Crianças e Jovens votou nas resoluções que visavam angariar a ratificação de todos os países-membros das Américas em relação às convenções referentes ao trabalho noturno e a idade de admissão dos adolescentes ao trabalho, assim como a elevar o limite mínimo estabelecido para esta idade $\underline{\underline{11}}$. Assunto polêmico por natureza, este último aspecto relacionado a idade mínima recebeu da Comissão uma posição “mais moderada” $\underline{12}$, tendo como meta principal incitar a OIT no prosseguimento de um estudo que pudesse apresentar uma medida ideal. O discurso de Allanita DinizGonzalves é representativo quanto às necessidades e entraves regionais que cercavam boa parte dos países ali presentes, como os altos índices de mortalidade infantil. Somada a isso, a fala dela ainda enfatiza a importância da assistência à maternidade e à infância como uma questão-chave de política econômica:

A forte mortalidade infantil que constitui um dos principais obst áculos ao aumento rápido da população e ao povoamento de territórios ainda inabitados mostra que a proteção à maternidade e à infância em nosso continente não é apenas um dever humanitário, mas também um meio de 
contribuir para a solução de certas dificuldades econômicas de importância capital. $\underline{13}$

Uma crítica mordaz feita sobre o próprio país anfitrião diante de todo o continente e dos representantes da Repartição Internacional do Trabalho foi executada pela Srta. Ramírez, delegada operária do Chile:

Antes de terminar, desejo referir-me que a Delega ção operária chilena apoiou a moção apresentada pela Delegação governamental dos Estados Unidos, no sentido de fixar a idade de dezesseis anos como idade mínima de admissão das crianças ao trabalho. Um exemplo do que ocorre por não legislar-se de forma efetiva sobre esta matéria, temos em nosso país no caso da greve das crianças da Cristalería de Chile, em que somente lhes pagam o miserável salário de \$ 4,50 semanais, (...); neste momento essas crianças, desnutridas e famintas, têm sido empurradas a uma greve em defesa de suas vidas. Se trata de crianças de idade entre nove e dezoito anos, totalmente indefesas. $\underline{14}$

De forma contundente, esse discurso atesta a recente reflexão do historiador Patricio González (2015), sobre a Conferência de Santiago: "os discursos que se seguiram em cada uma das sessões foram reafirmando a conviç̧ão dos delegados dos trabalhadores que a Conferência era um espaço público e democrático, que avançava em equilibrar direitos e deveres trabalhistas, de forma tripartida, e ademais legitimava demandas sociais e políticas da classe trabalhadora na presença de políticos, capitalistas e burocratas” (p.114, tradução livre). Nesse sentido, a ácida denúncia feita por Ramírez, combativa como são os discursos dos representantes operários na OIT, desnuda um dos principais impedimentos para a efetiva prática da legislação trabalhista: a ausência de fiscalização regular, o que acaba por inserir mão de obra abaixo da idade mínima legal no mercado de trabalho e submetida a remunerações irrisórias. Nesse caso, crianças chilenas de nove a treze anos, proibidas de laborar pela lei nacional que permitia somente a partir dos quatorze anos de idade para as atividades industriais $\frac{15}{}$.

O discurso da delegada governamental dos Estados Unidos, Frieda Miller, toca numa das questões mais sensíveis para a Comissão e, talvez, para a própria Conferência de Santiago: a fixação da idade mínima, defendida pelo governo estadunidense, em dezesseis anos de idade para a admissão ao emprego. Tendo sua justificativa baseada na importância que a medida traria para a elevação das condições de vida dos trabalhadores, Miller ressalta o imperativo de eliminar o trabalho de menores:

Se queremos colaborar de forma eficaz, como j á dissemos muitas vezes nesta conferência, para a melhoria da sociedade humana, temos que acabar com essa exploração de crianças, e se não solucionarmos esse problema, muitas das esplêndidas recomendações que foram feitas na Repartição Internacional do Trabalho não serão capazes de ser executadas. $\frac{16}{}$

Além disso, essa questão resvala numa contradição, também exposta por Miller, entre o trabalho excessivamente precoce e os ideais da “democracia moderna” $\underline{17}$. Sobre os Estados Unidos, Peter Stearns (2006) chama a atenção para o fato de que em 1904 houve a criação do The National Child Labor Reform Committe (Comitê Nacional de Reforma do Trabalho Infantil), instituição que não hesitou em tornar públicas, através da imprensa, as más condições de vida e trabalho de menores de idade. Stearns (2006) também lembra o paradoxo que essa questão evocava nos distintos grupos sociais: para os reformadores, "as crianças deveriam ter o direito de estar a salvo do trabalho, mesmo nas fazendas, e esse direito estava acima do pátrio poder de obrigá-las a trabalhar” (p. 148). Contudo, esse não era o mesmo sentimento compartilhado pelo empresariado que não se furtava de apresentar os benefícios do trabalho precoce. Tal realidade foi sendo transformada gradativamente, "mediante uma combinação de mudanças na indústria, de leis incluindo a obrigatoriedade escolar e as decisões dos próprios pais, o trabalho infantil começou a declinar" (Stearns, 2006, p. 148). 
Por fim, para efetivar as votações, a Comissão do Trabalho das Mulheres, de Crianças e dos Jovens, composta por dez representantes dos governos, cinco dos patrões e cinco dos trabalhadores, adotou o chamado Sistema Riddel em que cada membro das delegações patronais e operárias tem direito a dois votos e cada delegado governamental, a um voto. Totalizando cinco sessões de discussão, a Comissão analisou minuciosamente o Informe preparado pela Repartição Internacional do Trabalho sobre as condições de trabalho das mulheres, crianças e jovens.

Terminado o exame das condições de trabalho das mulheres, a presidente da Comissão abriu as discussões relacionadas às condições de trabalho das crianças e dos jovens. Iniciando as proposições, a delegação governamental da Argentina exortou os países que ainda não haviam internalizado as convenções relativas à idade mínima de admissão ao trabalho (industrial, marítimo, agrícola e não industriais), como também as normas sobre o trabalho noturno de crianças e exame médico dos jovens empregados a bordo de navios, que o fizesse o quanto antes. Um ponto importante na ponderação dos argentinos foi a indicação direcionada ao Conselho de Administração da Repartição Internacional do Trabalho para que se pudesse levar em consideração -para inclusão desse assunto na ordem do dia de uma próxima reunião da Conferência Internacional do Trabalho- a exigência do exame médico para os menores de idade que fossem pleitear vagas em trabalhos industriais, e não somente para a atividade a bordo de navios $\frac{18}{}$, como até então. Esta resolução foi aprovada por unanimidade $\underline{19}$.

Finalmente, na sequência, a presidente pôs em discussão a resolução proposta pela delegação governamental dos EUA que almejava elevar a idade mínima para a admissão ao trabalho em dezesseis anos. Apoiada pelos delegados governamentais do Uruguai e Canadá, como também pela delegação dos trabalhadores do Chile, essa ousada resolução encontrou a oposição da delegação governamental e patronal do Brasil, além dos delegados patronais do Uruguai e Chile, bem como a negativa do delegado dos trabalhadores da Bolívia $\underline{20}$. Não obtendo o consenso visado pelo governo estadunidense, o delegado governamental uruguaio propôs uma emenda ao texto solicitando ao Conselho de Administração o estabelecimento do procedimento para a revisão das convenções internacionais atinentes ao trabalho infanto-juvenil; a emenda foi aprovada por dez votos contra dois. Após ser modificada a resolução foi aprovada por unanimidade.

Calcanhar de Aquiles na legislação de vários países, a definição da idade mínima para o trabalho sem dúvidas que abalava inúmeros interesses e projetos nacionais. A proposta estadunidense, caso fosse aceita integralmente e de imediato em Santiago, numa outra conjectura certamente encontraria entraves na plenária da OIT em Genebra, onde uma profusão de economias e culturas ali representadas utilizava mão de obra infantil nos mais diversos setores como atesta a Tabela 1 sobre a admissão para ocupações não industriais:

Tabela 1. Idade de admissão para o trabalho não industrial, 1935

\begin{tabular}{|c|c|}
\hline Países & Trabalho em geral \\
\hline Convenção sobre idade mínima (trabalhos não industriais) & $\mathbf{1 4}$ \\
\hline Argentina & 12 \\
\hline Bolívia & 10 \\
\hline Brasil & 12 \\
\hline Canadá & 14 \\
\hline Manitoba & 12 \\
\hline Chile & 11 \\
\hline Colômbia & 14 \\
\hline Equador & 14 \\
\hline Guatemala & 12 \\
\hline México & \\
\hline
\end{tabular}




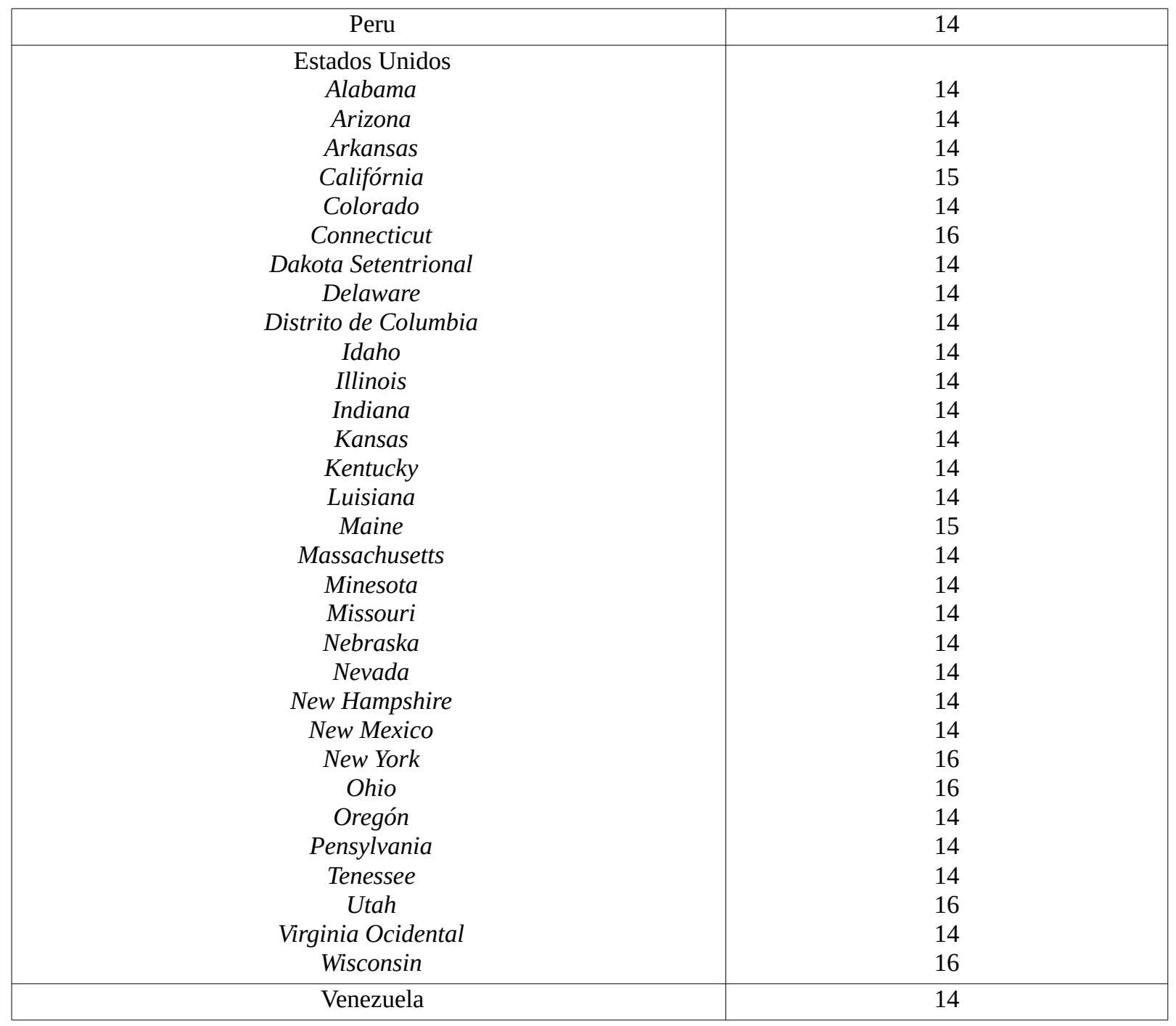

Fonte: Conferencia del Trabajo de los Estados de América Miembros de la Organización Internacional del Trabajo (Santiago de Chile, enero de 1936). (1935). Informe sobre el trabajo de los niños y de los jóvenes. Primera cuestión del orden del día. Gibebra: Oficina Internacional del Trabajo. pp. 27-30.

Como se percebe na Tabela 1, entre os países americanos, províncias canadenses e estados dos EUA que estipularam idades mínimas para o trabalho não industrial, a legislação da Argentina, Bolívia, Brasil, Chile, Colômbia e México estavam abaixo da idade piso preconizada pela Convenção n 33, de 1932. Até junho de 1938, apenas seis países haviam ratificado essa convenção: Áustria, Bélgica, Cuba, Espanha, Países Baixos e Uruguai $\underline{21}$.

Outra resolução proposta pela delegação governamental dos Estados Unidos referia-se a criação de “departamentos da infância” nos Ministérios do Trabalho dos países americanos o quanto antes, também aprovada por unanimidade. Digno de nota é o discurso de embasamento utilizado para essa proposição: "considerando que as questões relativas ao trabalho e às condições de vida das crianças da classe trabalhadora são as que têm mais importância social, e as que a Organização Internacional do Trabalho sempre olhou com mais interesse”를 . De acordo com essa proposta, um estudo sistemático sobre o trabalho de crianças e jovens, feito por um departamento técnico especialmente criado para tal objetivo, contribuiria de maneira mais eficaz para o equacionamento das questões a elas associadas.

Houve, ainda, a votação de uma resolução apresentada pelo delegado do governo brasileiro: "que se inclua, quando oportuno, na ordem do dia de uma das reuniões da Conferência Internacional do Trabalho, a questão 
relativa ao estudo das medidas que se impõem e das condições necessárias para o estabelecimento de colônias de férias destinadas aos menores que trabalham”르. Aceita por unanimidade, essa resolução descortina o tácito posicionamento dos governos de alguns países, como o Brasil, que preferia manifestar a manutenção do trabalho infantojuvenil -ainda que reconhecendo publicamente os seus malefícios- em vez do efetivo combate, como demonstrou ostensivamente o governo estadunidense.

O delegado governamental do Brasil também propôs uma resolução, aprovada com êxito, que visava exonerar de toda contribuição ou imposto os estabelecimentos particulares de educação gratuita profissional. Por fim, o delegado patronal do Chile sugeriu que os países procurassem estabelecer o maior número possível de escolas rurais com o propósito de facilitar o acesso das crianças do campo ao ensino público. Contudo, o projeto de resolução deixava registrado que os programas a serem elaborados deveriam ter "em conta a necessidade de permitir aos seus alunos o trabalho no campo" $\underline{24}$. A proposição também foi adotada por unanimidade. Esta última resolução, aprovada pela Comissão do Trabalho das Mulheres, de Crianças e dos Jovens, toca numa questão especialmente complexa em termos de legislação: o trabalho infantil na agricultura $\frac{25}{}$, objeto de regulamentação pela OIT desde 1921, através da Convenção ${ }^{\circ} 10$, que estabeleceu que as crianças que tivessem idade inferior a quatorze anos não poderiam ser empregadas ou trabalhar em qualquer empresa agrícola, pública ou privada, ou em qualquer ramo da mesma, exceto fora das horas fixadas para a frequência escolar. Caso fossem empregadas fora do horário escolar, o emprego não deveria ser de natureza a prejudicar sua frequência na escola. O próprio estudo fomentado pela OIT em 1935 evidencia que a regulamentação direta do trabalho de crianças e jovens na agricultura não está tão desenvolvida como, por exemplo, a regulação para o trabalho industrial $\underline{26}$. Na América Latina, apenas a Argentina e o Uruguai possuíam leis que estabeleciam uma idade específica para a admissão ao trabalho agrícola, fixada em doze anos $\underline{27}$.

A despeito de toda a burocracia pertencente aos ordenamentos jurídicos nacionais e outras questões emanadas de interesses de ordem política, até o final de junho de 1938 as onze convenções da OIT relativas ao trabalho infantojuvenil haviam sido ratificadas pelos países mencionados na Tabela 2:

Tabela 2. Convenções relativas ao trabalho de crianças e jovens ratificadas até junho de 1938

\begin{tabular}{|c|c|c|c|}
\hline $\begin{array}{l}\text { C. } 5 \\
(1919)\end{array}$ & $\begin{array}{l}\text { C. } 7 \\
(1920)\end{array}$ & $\begin{array}{l}\text { C. 10 } \\
(1921)\end{array}$ & $\begin{array}{l}\text { C.15 } \\
(1921)\end{array}$ \\
\hline $\begin{array}{l}\text { As crianças menores } \\
\text { de } 14 \text { anos não } \\
\text { poderão ser } \\
\text { empregadas em } \\
\text { trabalhos industriais. }\end{array}$ & $\begin{array}{l}\text { As crianças menores } \\
\text { de } 14 \text { anos não } \\
\text { poderão ser } \\
\text { empregadas em } \\
\text { trabalhos marítimos. }\end{array}$ & $\begin{array}{l}\text { As crianças menores } \\
\text { de } 14 \text { anos não } \\
\text { poderão ser } \\
\text { empregadas na } \\
\text { agricultura durante o } \\
\text { horário escolar. }\end{array}$ & $\begin{array}{l}\text { Os jovens menores } \\
\text { de } 18 \text { anos não } \\
\text { poderão ser } \\
\text { empregados a bordo } \\
\text { de navios como } \\
\text { estivadores ou } \\
\text { foguistas. }\end{array}$ \\
\hline $\begin{array}{l}\text { Ratificada por } 28 \\
\text { Estados }\end{array}$ & $\begin{array}{l}\text { Ratificada por } 32 \\
\text { Estados }\end{array}$ & $\begin{array}{l}\text { Ratificada por } 20 \\
\text { Estados }\end{array}$ & $\begin{array}{l}\text { Ratificada por } 32 \\
\text { Estados }\end{array}$ \\
\hline $\begin{array}{l}\text { Albânia } \\
\text { Argentina } \\
\text { Áustria }^{1} \\
\text { Bélgica } \\
\text { Brasil } \\
\text { Bulgária } \\
\text { Chile } \\
\text { Checoslováquia } \\
\text { Colômbia }\end{array}$ & $\begin{array}{l}\text { Alemanha² } \\
\text { Argentina } \\
\text { Bélgica } \\
\text { Bulgária } \\
\text { Brasil } \\
\text { Canadá } \\
\text { Chile } \\
\text { China } \\
\text { Colômbia }\end{array}$ & $\begin{array}{l}\text { Argentina } \\
\text { Áustria }^{1} \\
\text { Bélgica } \\
\text { Bulgária } \\
\text { Chile } \\
\text { Checoslováquia } \\
\text { Cuba } \\
\text { República } \\
\text { Dominicana }\end{array}$ & $\begin{array}{l}\text { Alemanha }^{2} \\
\text { Argentina } \\
\text { Austrália } \\
\text { Bélgica } \\
\text { Bulgária } \\
\text { Canadá } \\
\text { Chile } \\
\text { China } \\
\text { Colômbia }\end{array}$ \\
\hline
\end{tabular}




\begin{tabular}{|c|c|c|c|}
\hline $\begin{array}{l}\text { Cuba } \\
\text { Dinamarca } \\
\text { República } \\
\text { Dominicana } \\
\text { Espanha } \\
\text { Estônia } \\
\text { Grã-Bretanha } \\
\text { Grécia } \\
\text { Irlanda } \\
\text { Japão } \\
\text { Letônia } \\
\text { Luxemburgo } \\
\text { Nicarágua } \\
\text { Noruega } \\
\text { Países Baixos } \\
\text { Polônia } \\
\text { Romênia } \\
\text { Suíça } \\
\text { Uruguai } \\
\text { Iugoslávia }\end{array}$ & $\begin{array}{l}\text { Cuba } \\
\text { Dinamarca } \\
\text { República } \\
\text { Dominicana } \\
\text { Espanha } \\
\text { Estônia } \\
\text { Finlândia } \\
\text { Grã-Bretanha } \\
\text { Grécia } \\
\text { Hungria } \\
\text { Irlanda } \\
\text { Itália } \\
\text { Japão } \\
\text { Letônia } \\
\text { Luxemburgo } \\
\text { Nicarágua }{ }^{2} \\
\text { Noruega } \\
\text { Países Baixos } \\
\text { Polônia } \\
\text { Romênia } \\
\text { Suécia } \\
\text { Uruguai } \\
\text { Iugoslávia }\end{array}$ & $\begin{array}{l}\text { Espanha } \\
\text { Estônia } \\
\text { Hungria } \\
\text { Irlanda } \\
\text { Itália } \\
\text { Japão } \\
\text { Luxemburgo } \\
\text { Nicarágua } 2 \\
\text { Polônia } \\
\text { Romênia } \\
\text { Suécia } \\
\text { Uruguai }\end{array}$ & $\begin{array}{l}\text { Cuba } \\
\text { Dinamarca } \\
\text { Espanha } \\
\text { Estônia } \\
\text { Finlândia } \\
\text { França } \\
\text { Grã-Bretanha } \\
\text { Grécia } \\
\text { Hungria } \\
\text { Índia } \\
\text { Irlanda } \\
\text { Itália } \\
\text { Japão } \\
\text { Letônia } \\
\text { Luxemburgo } \\
\text { Nicarágua }{ }^{2} \\
\text { Noruega } \\
\text { Países Baixos } \\
\text { Polônia } \\
\text { Romênia } \\
\text { Suécia } \\
\text { Uruguai } \\
\text { Iugoslávia }\end{array}$ \\
\hline $\begin{array}{l}\text { Convenção revisada } \\
\text { em } 1937\end{array}$ & $\begin{array}{l}\text { Convenção } \\
\text { revisada em } 1936\end{array}$ & & \\
\hline $\begin{array}{l}\text { As crianças menores } \\
\text { de } 15 \text { anos não } \\
\text { poderão ser } \\
\text { empregadas em } \\
\text { trabalhos industriais. } \\
\text { (O tempo transcorrido } \\
\text { desde a adoção desta } \\
\text { convenção revisada } \\
\text { não é suficiente para } \\
\text { que o procedimento } \\
\text { de ratificação tenha } \\
\text { dado resultados } \\
\text { concretos) }\end{array}$ & $\begin{array}{l}\text { As crianças menores } \\
\text { de } 15 \text { anos não } \\
\text { poderão ser } \\
\text { empregadas em } \\
\text { trabalhos marítimos. } \\
\text { Ratificada por } 2 \\
\text { Estados: } \\
\text { Bélgica } \\
\text { Noruega } \\
\text { (O tempo } \\
\text { transcorrido desde a } \\
\text { adoção desta } \\
\text { convenção revisada } \\
\text { não é suficiente para } \\
\text { que o procedimento } \\
\text { de ratificação tenha } \\
\text { dado resultados } \\
\text { concretos) }\end{array}$ & & \\
\hline
\end{tabular}

Tabela 2. (continuação)

\begin{tabular}{|l|l|l|l|}
\hline C. 33 & C. 6 & C. 16 & C. 52 \\
$(1932)$ & $(1919)$ & $(1921)$ & $(1936)$ \\
\hline
\end{tabular}




\begin{tabular}{|c|c|c|c|}
\hline $\begin{array}{l}\text { As crianças menores } \\
\text { de } 14 \text { anos não } \\
\text { poderão ser } \\
\text { empregadas em } \\
\text { nenhum trabalho não } \\
\text { previsto nas } \\
\text { convenções de 1919- } \\
\text { 1921, excetuando os } \\
\text { trabalhos rápidos } \\
\text { efetuados fora do } \\
\text { horário escolar por } \\
\text { crianças maiores de } \\
12 \text { anos. }\end{array}$ & $\begin{array}{l}\text { Os jovens menores } \\
\text { de } 18 \text { anos não } \\
\text { poderão ser } \\
\text { empregados à noite } \\
\text { na indústria, } \\
\text { excetuando os } \\
\text { jovens maiores de } 16 \\
\text { anos empregados em } \\
\text { trabalhos } \\
\text { necessariamente } \\
\text { contínuos. }\end{array}$ & $\begin{array}{l}\text { Os jovens menores } \\
\text { de } 18 \text { anos somente } \\
\text { poderão ser } \\
\text { empregados a bordo } \\
\text { de navios com a } \\
\text { prévia apresentação } \\
\text { de um certificado } \\
\text { médico que conste a } \\
\text { sua aptidão para o } \\
\text { referido trabalho. }\end{array}$ & $\begin{array}{l}\text { Os jovens menores } \\
\text { de } 16 \text { anos terão } \\
\text { direito, após um ano } \\
\text { de serviço contínuo, } \\
\text { a férias anuais com } \\
\text { pagamento de pelo } \\
\text { menos, doze dias } \\
\text { úteis. }\end{array}$ \\
\hline $\begin{array}{l}\text { Ratificada por } 6 \\
\text { Estados }\end{array}$ & $\begin{array}{l}\text { Ratificada por } 31 \\
\text { Estados }\end{array}$ & $\begin{array}{l}\text { Ratificada por } 33 \\
\text { Estados }\end{array}$ & $\begin{array}{l}\text { Ratificada por } 1 \\
\text { Estado }\end{array}$ \\
\hline $\begin{array}{l}\text { Áustria }^{1} \\
\text { Bélgica } \\
\text { Cuba } \\
\text { Espanha } \\
\text { Países Baixos } \\
\text { Uruguai }\end{array}$ & $\begin{array}{l}\text { Albânia } \\
\text { Argentina } \text { Áustria }^{1} \\
\text { Bélgica } \\
\text { Brasil } \\
\text { Bulgária } \\
\text { Chile } \\
\text { Cuba } \\
\text { Dinamarca } \\
\text { Espanha } \\
\text { Estônia } \\
\text { França } \\
\text { Grã-Bretanha } \\
\text { Grécia } \\
\text { Hungria } \\
\text { Índia } \\
\text { Irlanda } \\
\text { Itália } \\
\text { Letônia } \\
\text { Lituânia } \\
\text { Luxemburgo } \\
\text { México } \\
\text { Nicarágua }{ }^{2} \\
\text { Países Baixos } \\
\text { Polônia } \\
\text { Portugal } \\
\text { Romênia } \\
\text { Suíça } \\
\text { Uruguai } \\
\text { Venezuela } \\
\text { Iugoslávia }\end{array}$ & $\begin{array}{l}\text { Alemanha² } \\
\text { Argentina } \\
\text { Austrália } \\
\text { Bélgica } \\
\text { Brasil } \\
\text { Bulgária } \\
\text { Canadá } \\
\text { Chile } \\
\text { China } \\
\text { Colômbia } \\
\text { Cuba } \\
\text { Dinamarca } \\
\text { Espanha } \\
\text { Estônia } \\
\text { Finlândia } \\
\text { França } \\
\text { Grã-Bretanha } \\
\text { Grécia } \\
\text { Hungria } \\
\text { Índia } \\
\text { Irlanda } \\
\text { Itália } \\
\text { Japão } \\
\text { Letônia } \\
\text { Luxemburgo } \\
\text { México } \\
\text { Nicarágua² } \\
\text { Países Baixos } \\
\text { Polônia } \\
\text { Romênia } \\
\text { Suécia } \\
\text { Uruguai } \\
\text { Iugoslávia }\end{array}$ & $\begin{array}{l}\text { México } \\
\text { (O tempo } \\
\text { (ranscorrido desde a } \\
\text { adoção r desta } \\
\text { convenção não é } \\
\text { suficiente para que o } \\
\text { procedimento de } \\
\text { ratificação tenha } \\
\text { dado resultados } \\
\text { concretos) }\end{array}$ \\
\hline $\begin{array}{l}\text { Convenção revisada } \\
\text { em } 1937 \\
\text { As crianças menores } \\
\text { de } 15 \text { anos não } \\
\text { poderão ser } \\
\text { empregadas em }\end{array}$ & & & \\
\hline
\end{tabular}




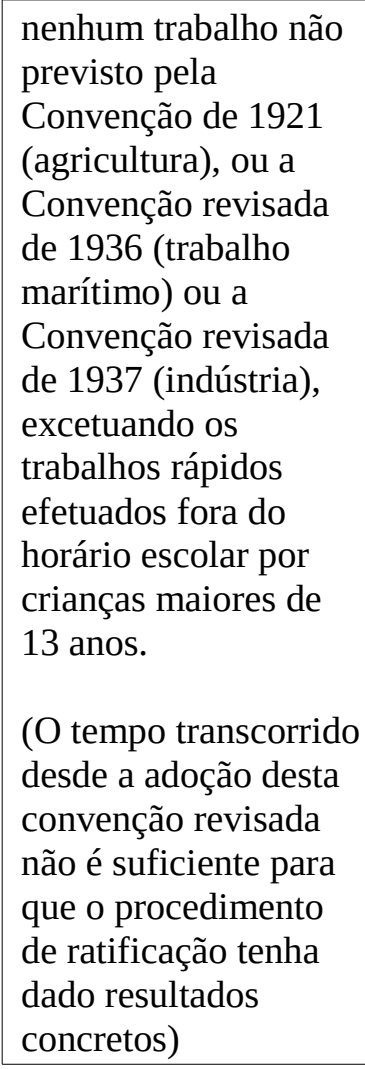

${ }^{1}$ Através de carta datada de 8 de abril de 1938, o Ministro do Trabalho da Alemanha notificou que a Áustria havia deixado de ser membro da Organização.

2 Alemanha e Nicarágua deixaram de ser membros da Organização em 21 de outubro de 1935 e em 27 de junho de 1938, respectivamente.

Fonte: OIT. (1938). La Organización Internacional del Trabajo y los problemas de la juventud. Ginebra: Oficina Internacional del Trabajo.

Sendo os quatorze anos a idade mínima comum dos textos das convenções da OIT, antes do período de revisão, muitos Estados-membros da Organização, americanos ou não, ainda resistiam em ratificá-las durante a década de 1930. Não há dúvidas que as condições econômicas de determinados países, imersos em realidades em que o pouco dinheiro angariado por crianças e jovens tinham peso significativo para o orçamento doméstico, os levasse a manter uma posição cautelosa quanto a delimitação de idades mínimas para o emprego.

A partir de 1936, como exposto na Tabela 2, surgiram textos revisados de três convenções, fator que elevou as idades mínimas para quinze anos de idade. Mesmo com esse aumento, ainda tímido, Smolin (2000) defende a ideia de que "a retórica e a terminologia da 'abolição do trabalho infantil' estavam ausentes das Convenções deste período” (p. 944, tradução livre). O que é notável em relação à matéria do trabalho infantojuvenil, na produção normativa da OIT, é a proibição a trabalhos considerados perigosos, como estivadores e foguistas, e o trabalho noturno quando o trabalhador estivesse com menos de dezoito anos (Cf. Dahlén, 2007, p. 227).

\section{A Conferência de Havana (Cuba, 1939)}

Se a Conferência de Santiago de 1936, de acordo com González (2015) foi "um estímulo para alcançar uma melhor compreensão dos problemas trabalhistas e sociais da região” (p. 115, tradução livre), a Conferência 
realizada em novembro de 1939 em Cuba deu a devida continuidade a tal propósito. Um detalhe em particular chama a atenção: o nome da comissão instalada para a discussão sobre o trabalho feminino e infantojuvenil. Suprimindo o termo crianças [niños], a intitulada Comissão do Trabalho das Mulheres e dos Jovens $\underline{28}$ da Conferência de Havana expressa claramente a política, que paulatinamente foi sendo agregada à opinião pública internacional, consagrada à eliminação do trabalho de crianças.

Assim como em Santiago, a Comissão teve como presidente uma mulher, Mary N. Winslow, curiosamente uma delegada governamental dos Estados Unidos, como também em 1936. Já a relatora foi Pilar Jorge de Tella, conselheira técnica da delegação governamental de Cuba. No conjunto, a Comissão foi composta por vinte membros, sendo dez delegados dos governos, cinco delegados patronais e cinco dos trabalhadores. O procedimento de votação, como ocorreu no Chile em 1936, foi conduzido através do sistema Riddell, em que cada delegado patronal e dos trabalhadores tem direito a dois votos, e os membros governamentais, cada um, tem direito a um voto $\underline{\underline{29}}$. Como foi apontado por Tella, a Comissão concentrou seus esforços e discussões em questões que vislumbrassem dar efetividade às resoluções aprovadas na Conferência de Santiago.

Desse modo, sua atividade foi pautada nos seguintes acordos: 1) a importância da ratificação das convenções revisadas sobre a idade mínima para admissão ao emprego de 1936 (trabalho marítimo) e de 1937 (trabalho industrial e não industrial) aos países que ainda não haviam feito, de modo a internalizar e reconhecer o lugar dos meios de educação e proteção social para todas as crianças que não haviam atingido a idade para o acesso formal ao mercado de trabalho, além da fixação de uma idade mais elevada para ocupações consideradas perigosas aos menores; 2) a exigência do certificado de aptidão física e legal do menor para a sua admissão ao emprego, subordinada aos resultados de um prévio exame médico; 3) o incentivo ao desenvolvimento de serviços destinados a proteger crianças desamparadas total ou parcialmente, de forma que elas não precisassem adentrar precocemente ao mundo do trabalho, somente que se preparassem para o “exercício de uma profissão”; 4) a proibição do trabalho noturno aos adolescentes, principalmente no setor industrial, medida também direcionada aos países pouco industrializados, como forma de prevenção; 5) a opção pela abolição do comércio ambulante realizado por menores de idade, além da recomendação para que os países americanos ratificassem a Convenção n 33 de 1932 e a Resolução nº 41 sobre trabalho ambulante realizado por menores em vias públicas e outros trabalhos não industriais; 6) apresentar aos países das Américas, a necessidade de observar, pela importância e significado, a recomendação adotada na XXV Conferência Internacional do Trabalho sobre a formação e aprendizagem profissional, incluindo em suas legislações, entre outras questões relacionadas, disposições que obrigassem os empregadores a admitir uma quantidade de aprendizes de maneira proporcional ao número de trabalhadores existentes no estabelecimento $\underline{\underline{30}}$.

Para contemplar tais metas, a Comissão ainda adicionou uma Recomendação ao Conselho de Administração sugerindo que solicite aos países do continente americano, que ainda não definiram uma legislação reguladora para a efetivação das convenções acerca do trabalho de mulheres e menores ou que, havendo promulgado, ainda não adotaram os princípios estabelecidos pela Conferência de Santiago, que incluíssem em suas leis mecanismos para instituir seções sobre mulheres e crianças em seus Ministérios do Trabalho ou outros órgãos com competência para aplicar essa legislação, com funcionários do governo e representantes dos trabalhadores $\underline{31}$.

Em suma, quatro resoluções específicas sobre o trabalho de menores se desdobraram da Conferência de Havana, debatidas e aprovadas pela Comissão do Trabalho das Mulheres e dos Jovens: Resolução sobre as condições de trabalho dos jovens, Resolução sobre o trabalho ambulante de menores, Resolução sobre aprendizagem, e a Resolução sobre os serviços administrativos para o trabalho de mulheres e menores. 
A primeira resolução, proposta pela delegação governamental estadunidense, abarcava diversas questões particulares sobre as condições de trabalho dos menores. Mirando elencar alguns princípios fundamentais para as agendas americanas, norteadores para uma política reguladora mais efetiva relacionada à matéria, além da exortação recorrente, direcionada ao Conselho de Administração da Repartição Internacional do Trabalho para que chamasse a atenção dos países americanos para os princípios discutidos e adotados: a) a idade de admissão para o emprego, conclamando os países que ainda não haviam ratificado as convenções revisadas sobre as idades mínimas para o trabalho marítimo (1936), industrial (1937) e não industrial (1937) que o fizessem, além de que reconhecessem a importância e necessidade dos meios de educação e proteção social às crianças que ainda não atingiram a idade para o trabalho, além da elevação da idade para as atividades consideradas perigosas para "a vida, saúde ou a moralidade do menor”; b) a aptidão para o trabalho, que deveria estar condicionada à expedição por autoridade competente, de uma certificação gratuita (proveniente de um exame médico) que comprovasse que o menor se encontrava em condições adequadas para o emprego, certificado também exigido àqueles que trabalhassem na rua por conta própria; c) o dever de impulsionar serviços especializados destinados à proteção de menores que se encontrassem em situação de desamparo, principalmente aqueles que ainda não possuíssem a idade legal para a admissão ao trabalho, de modo a "evitar que [fossem] utilizados prematuramente", além disso, também havia o destaque para que essas crianças recebessem uma educação, durante esse período, que as preparasse para um bom desempenho de um trabalho futuro, como também que recebessem o apoio para a sua inserção em empregos adequados que pudessem permitir o seu desenvolvimento pessoal; d) a proibição do trabalho noturno aos jovens abaixo dos dezoito anos, especialmente na indústria, por todos os países, incluindo os pouco industrializados, além de estabelecer a obrigação do descanso de onze horas consecutivas em cada período de vinte e quatro horas.

A segunda resolução, sobre o trabalho ambulante de menores $\frac{32}{}$, apresentada pela delegação governamental cubana, provocou um intenso debate entre os membros da Comissão que concordaram que se tratava de um “problema cuja solução prática é particularmente difícil” $\underline{33}$. O que ficou evidenciado é a indicação para o que países americanos sigam os preceitos contidos na Convenção n ${ }^{33}$, de 1932, e na Recomendação n 41 , relativas aos trabalhos não industriais e com regras sobre as atividades realizadas em vias públicas. Por nove votos contra quatro a Comissão optou pela indicação da total abolição do comércio ambulante feito por menores, apesar de reconhecer que esse ideal encontraria sérios problemas para sua efetivação num futuro imediato para a maioria dos países $\underline{34}$. Todavia, o texto final dessa resolução cumpre o papel de endossar o indicativo para que as leis americanas contemplassem as diversas ocupações atinentes ao espaço público, como a entrega de recados, distribuição e venda de jornais, bilhetes de loteria, venda de frutas e flores e afins $\underline{35}$.

A questão da aprendizagem também foi alvo de uma resolução. A Comissão recebeu duas propostas relativas à aprendizagem, uma do membro governamental de Cuba e outra do delegado dos trabalhadores do México. Combinadas num único texto, a proposta reforçou a necessidade de observar a Recomendação sobre formação profissional, que declara que nos países onde não há uma quantidade suficiente de escolas profissionais seria desejável que empresas assumissem os custos da formação profissional de um número de jovens trabalhadores em proporção ao número de seu pessoal; e a Recomendação sobre a aprendizagem, que prevê a tomada de medidas para o controle do número de aprendizes e a duração da aprendizagem; ambas as recomendações foram aprovadas pela XXV Conferência Internacional do Trabalho. Nesse sentido, além de chamar a atenção dos países americanos para a importância da observação às Recomendações supracitadas, esta resolução ainda elenca sete dispositivos para servir de modelo às normas nacionais que poderiam ser arquitetadas 
(a) que os empregadores admitam um n úmero de aprendizes que as leis determinarão, proporcional ao número de trabalhadores que empregam (...);

(b) que a admiss ão à aprendizagem dos menores de quinze anos seja proibida, exceto quando existam razões especiais, cujos casos a aprendizagem será estritamente controlada pelas autoridades

(c) que não se admita aprendizes sem remuneração

(d) que se fixe a duração da aprendizagem para impedir que o empresário utilize aprendizes como trabalhadores, com prejuízos aos direitos destes e também dos aprendizes;

(e) que se crie um sistema baseado na constituição de organismos tripartidos responsáveis pela supervisão da qualificação e ascensão regular dos aprendizes em proporção ao aumento de sua capacidade (...). Estes organismos serão compostos por um número igual de representantes governamentais, empregadores e trabalhadores.

(f) que se realizem investigações em cada país para estabelecer as indústrias ou as atividades que devem ser aceitos os aprendizes, com o objetivo fundamental de fazer da aprendizagem um instrumento para melhorar a qualificação dos trabalhadores;

(g) que por cada técnico estrangeiro que seja empregado em toda indústria se admitia, pelo menos, na mesma, um aprendiz nativo ou naturalizado. $\underline{\underline{36}}$

A última resolução aprovada por esta Comissão em Havana, por sua vez, foi dedicada aos serviços administrativos para o trabalho de mulheres e menores $\frac{37}{}$. Reconhecendo o desafio da aplicação efetiva da legislação direcionada ao labor feminino e infantojuvenil, a resolução recomenda ao Conselho de Administração que solicite aos países que ainda o fizeram que sigam os princípios da Conferência de Santiago e estabeleçam seções voltadas ao trabalho das mulheres e menores em seus respectivos Ministérios do Trabalho ou órgãos competentes para tais prerrogativas, além da necessidade de inserir representantes dos próprios trabalhadores em tais organismos.

Diante dessas duas conferências americanas consumadas no entreguerras, uma ponderação se faz necessária: os pequenos trabalhadores -como Esmeralda Moura (2013) comenta- se tornaram "símbolos por excelência da desenfreada exploração do trabalho" (p. 260) e as tentativas de normatização, incluindo a intrépida meta de abolição dessa mão de obra para algumas ocupações, se fizeram permeadas por uma miríade de vozes locais e internacionais ao passo de avanços e recuos.

Nessa perspectiva, a contribuição epistemológica da história global ultrapassa a compreensão que almeja estudar os processos históricos somente por uma visão telescópica. O historiador do global, como expõe Sandrine Kott (2015), “dá uma nova atenção às conexões, às circulações, aos intercâmbios, tradicionalmente negligenciados num quadro estritamente monográfico” (pp. 131-132).

\section{Considerações finais}

Numa encruzilhada entre os desígnios da lei, o poder das tradições e a força de motivações econômicas diversas, sobretudo no mundo do entreguerras, cercado pelas consequências da Grande Depressão, as Conferências Americanas do Trabalho ressoaram as múltiplas convicções relacionadas ao trabalho infantojuvenil. O trabalho das duas comissões instaladas tanto em Santiago (1936) quanto em Havana (1939) para estudar e apresentar resoluções relacionadas às condições de trabalho de crianças e jovens permite sublinhar o impacto e o lugar de destaque que as Conferências, e a própria OIT, deram às especificidades e a 
urgência da internalização por parte dos países-membros da produção normativa dedicada à matéria.

De forma evidente, o pensamento que vê a criança como o agente do futuro, recorrente desde o século XIX, ganhava espaço na opinião pública internacional. A esfera do trabalho, tendo a OIT como organismo ícone, não ficou indiferente a tal lógica. Discursos e proposições focados em apresentar soluções para a regulação do labor dos menores, claramente pautados por questões voltadas ao desenvolvimento físico e psíquico desses sujeitos, também reservava em seu domínio a justificativa de proteger o trabalhador do amanhã. Aliada a esse fundamento estava a recomendação para que houvesse, de fato, uma instrução mais sólida antes da entrada no mercado de trabalho.

Para além das exceções legais apregoadas pelos instrumentos jurídicos emanados das Conferências Americanas e da Organização, como as resoluções, convenções e recomendações em que praticamente se fechava os olhos para o trabalho precoce que estivesse sob o manto da estrutura familiar ou fora do horário escolar; diante da tentativa de regulamentar -e encontrar consenso- para inibir e abolir a exploração do trabalho infantojuvenil, o maior desafio encontrado pela OIT foi a ratificação dos Estados-membros e a posterior aplicação efetiva de tais medidas, questões constantes em ambas as Conferências aqui analisadas e objeto de lamentação explícita nas conclusões do Informe de $1939 \underline{38}$.

As experiências e visões compartilhadas nos dois momentos, por outro lado, indicam variados projetos econômicos e políticas assistenciais vigentes nos países americanos, iguais na presença -ainda que em diferentes níveis- da mão de obra infantil e juvenil, desiguais nos mecanismos de normatização, regulação e fiscalização dessa população economicamente ativa. Sob esse prisma, também cabe destacar a heterogeneidade das infâncias e juventudes, assim como as condições que as levam para o mundo do trabalho. Desse modo, as resoluções propaladas em Santiago e em Havana não serviram apenas para emitir propostas de regulamentação sobre o trabalho infantojuvenil, mas também ajudaram a conformar modelos ideais de infância e juventude.

Em acordo com o propósito da OIT, que possuía (e ainda possui) representantes dos trabalhadores em seu próprio Conselho de Administração, assim como nas delegações dos países-membros, precisa-se identificar as vozes das próprias crianças e jovens trabalhadores e desvendar suas impressões sobre a lei e a aplicação (ou a omissão) das diversas normas que repercutiam diretamente sobre suas vidas. Estudos que alcancem múltiplas fontes de distintos âmbitos, como diários, entrevistas e processos judiciais são poderosos aliados às pesquisas que têm a OIT e a questão da normatização do trabalho infantojuvenil como campo de análise.

De volta ao romance de Jorge Amado (2008 [1936]), não podemos nos preservar de tentar imaginar o milagre tão sonhado pela professorinha Dulce, um milagre que pudesse mudar as vidas daqueles homens, mulheres e crianças que viviam à beira do cais e laboravam no mar da Bahia. Um milagre que pudesse, talvez, fazer com que Guma e outros meninos não precisassem conduzir saveiros e levantar sacos de farinha aos onze anos de idade.

\section{Notas}

1 Conferencia del Trabajo de los Estados de América miembros de la Organización Internacional del Trabajo (Santiago de Chile, 2 al 14 de Enero de 1936). (1936). Actas de las sesiones. Ginebra: Oficina Internacional del Trabajo. p. XVI.

2 Ibidem, pp. XVII-XVIII.

$\underline{3}$ International Labour Office. (1935). Children and Young Persons Under Labour Law. Geneva: International Labour Office. pp. 68, 77. 
4 Conferencia del Trabajo de los Estados de América miembros de la Organización Internacional del Trabajo (Santiago de Chile, 2 al 14 de Enero de 1936). Op. cit., p. XVIII.

$\underline{5}$ Conferencia Internacional del Trabajo. (1936). Memoria del Director. Ginebra: Oficina Internacional del Trabajo. p.71.

6 Conferencia del Trabajo de los Estados de América miembros de la Organización Internacional del Trabajo (Santiago de Chile, 2 al 14 de Enero de 1936). Op. cit., pp. 3-4.

7 Ibidem, p.6.

$\underline{8}$ Idem.

9 Ibidem, p. 10.

10 Ibidem, p. 13.

11 Ibidem, p. 265.

12 Idem.

13 Ibidem, p. 266.

14 Ibidem, p. 273.

15 Código del Trabajo de Chile de 1931. Decreto con fuerza de ley № 178. Santiago, 13 de Mayo de 1931.

16 Conferencia del Trabajo de los Estados de América miembros de la Organización Internacional del Trabajo (Santiago de Chile, 2 al 14 de Enero de 1936). Op. cit., p. 274.

17 Ibidem, p. 275.

18 Convenção n. 16, de 1921.

19 Conferencia del Trabajo de los Estados de América miembros de la Organización Internacional del Trabajo (Santiago de Chile, 2 al 14 de Enero de 1936). Op. cit., pp. 370-371.

$\underline{20}$ Idem.

21 OIT. (1938). La Organización Internacional del Trabajo y los problemas de la juventud. Ginebra: Oficina Internacional del Trabajo.

22 Conferencia del Trabajo de los Estados de América miembros de la Organización Internacional del Trabajo (Santiago de Chile, 2 al 14 de Enero de 1936). Op. cit., p. 372.

$\underline{23}$ Ibidem, p. 373.

24 Idem.

$\underline{25}$ Conferir o texto de Fyfe, A. (2009). Worst Forms of Child Labor: Agriculture. En: H. D. Hindman (Ed.). The World of Child Labor: An Historical and Regional Survey. (pp. 82-85). Armonk: M. E. Sharpe.

26 Conferencia del Trabajo de los Estados de América Miembros de la Organización Internacional del Trabajo (Santiago de Chile, enero de 1936). (1935). Informe sobre el trabajo de los niños y de los jóvenes. Primera cuestión del orden del día. Gibebra: Oficina Internacional del Trabajo. p. 20.

27 Ibidem, p. 21. 
$\underline{28}$ Segunda Conferencia del Trabajo de los Estados de América miembros de la Organización Internacional del Trabajo (La Habana, Cuba, Noviembre 21 a Diciembre 2 de 1939). (1941). Actas de las sesiones. Montreal: Oficina Internacional del Trabajo.

$\underline{29}$ Ibidem, p. 273.

30 Ibidem, pp. 200-201.

31 Ibidem, p. 202.

32 Ibidem, pp. 293-294.

33 Ibidem, p. 288.

34 Ibidem, p. 289.

$\underline{35}$ Ibidem, p. 294.

36 Ibidem, pp. 294-295.

37 Ibidem, p. 295.

$\underline{38}$ Segunda Conferencia del Trabajo de los Estados de América miembros de la Organización Internacional del Trabajo (La Habana - Noviembre, 1939). (1939). Informe acerca de las medidas tomadas para dar cumplimiento a las resoluciones adoptadas por la Conferencia de Santiago de Chile. Ginebra: Oficina Internacional del Trabajo. p.138.

\section{Referências}

Amado, J. (2008 [1936]). Mar morto. São Paulo: Companhia das Letras.

Dahlén, M. (2007). The Negotiable Child. The ILO Child Labour Campaign 1919-1973 (Tesis doctoral, Uppsala Universitet). Recuperada de http://uu.diva-portal.org/smash/get/diva2:169702/FULLTEXT01.pdf

González, P. H. (2015). Las Conferencias Americanas del Trabajo y el debate sobre las condiciones laborales del proletariado de América Latina, 1936-1946. Revista Mundos do Trabalho, 7(13), 105-128.

Heywood, C. (2004). Uma história da infância: da Idade Média à época contemporânea no Ocidente. Porto Alegre: Artmed.

Kott, S. (2015). Para uma história social das organizações internacionais. A OIT e a internacionalização dos saberes sociais. En M. B. Jerónimo; J. P. Monteiro (Eds.), Os Passados do Presente: Internacionalismo, Imperialismo e a Construção do Mundo Contemporâneo (pp.131-158). Coimbra: Almedina.

Moura, E. B. B. (2013). Crianças operárias na recém-industrializada São Paulo. En M. D. Priore (Ed.). História das crianças no Brasil (7ª ed., pp. 259-288). São Paulo: Contexto.

Nascimento, A. M. (2010). Curso de direito do trabalho: história e teoria geral do direito do trabalho: relações individuais e coletivas do trabalho. São Paulo: Saraiva.

OIT (1938). La Organización Internacional del Trabajo y los problemas de la juventud. Ginebra: Oficina Internacional del Trabajo.

OIT (s.f.). História. Recuperado de http://www.oitbrasil.org.br/content/hist\%C3\%B3ria 
Rodgers, G. et al. (2009). La Organización Internacional del Trabajo y la lucha por la justicia social, 19192009. Ginebra: OIT.

Smolin, D. M. (2000). Strategic Choices in the International Campaign Against Child Labor. Human Rights Quarterly, 22(4), 942-987.

Smolin, D. M. (1999). Conflict and Ideology in the International Campaign Against Child Labour. Hofstra Labor and Employment Law Journal, 16(2), 383-451.

Stearns, P. N. (2006). A infância. São Paulo: Contexto.

Süssekind, A. (1987). Direito Internacional do Trabalho (2a ed.). São Paulo: LTr.

Zelizer, V. (1985). Pricing the Priceless Child: the Changing Social Value of Children. New York: Basic Books. 